\section{Integrating social media and CSR into strategic planning for a competitive advantage}

\begin{tabular}{|c|c|}
\hline $\begin{array}{l}\text { The current theory for strategic } \\
\text { planning involves assessing } \\
\text { the business environment and } \\
\text { identifying key assets within an } \\
\text { organisation. Social media and } \\
\text { corporate social responsibility } \\
\text { (CSR) are currently considered } \\
\text { unnecessary in strategy } \\
\text { formulation. However, research } \\
\text { conducted by Dr Gordon } \\
\text { Bowen, associate lecturer at } \\
\text { Northumbria University amongst } \\
\text { other institutions, indicates } \\
\text { that incorporating social media } \\
\text { and CSR into an organisation's } \\
\text { strategy can allow for more } \\
\text { dynamic and data-driven } \\
\text { decision making, giving them a } \\
\text { competitive advantage. }\end{array}$ & $\begin{array}{l}\text { he current framework for strategic } \\
\text { planning is based predominantly } \\
\text { on environmental or } \\
\text { competencies analysis. Environmental } \\
\text { analysis means examining all the } \\
\text { internal and external factors within } \\
\text { an organisation, including its } \\
\text { strengths, weaknesses, threats, and } \\
\text { opportunities. Competencies analysis } \\
\text { is the identification and evaluation } \\
\text { of a firm's capabilities. Both analysis } \\
\text { methods are currently integral to the } \\
\text { strategic planning process. However, } \\
\text { Dr Gordon Bowen aims to show how } \\
\text { the integration of social media and } \\
\text { corporate social responsibility (CSR) into } \\
\text { strategic planning can complement and } \\
\text { improve existing strategic development. } \\
\text { CSR and social media should no } \\
\text { longer be mere afterthoughts, applied } \\
\text { incongruently within the strategic plan. }\end{array}$ \\
\hline
\end{tabular}

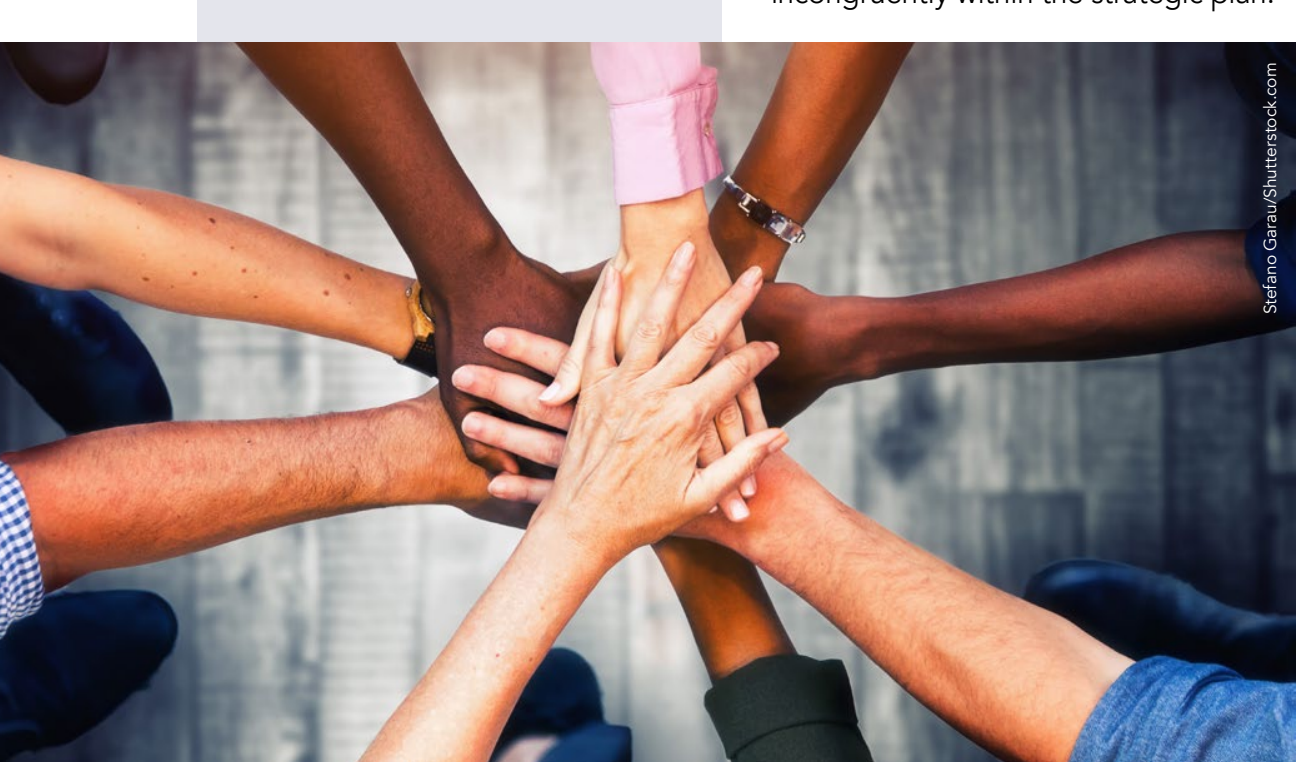

Through his research, Dr Gordon Bowen explains why CSR and social media should be brought to the forefront in work in tandem with current tactics to give companies a more comprehensive strategy and a competitive advantage.

THE "NEW NORMAL"

The COVID-19 pandemic pushed companies to adapt and refine their practices quickly to stay alive. The "new normal" introduced by the pandemic has ed to increased pressure on organisation to have good environmental practices and ethics at their core.

The pandemic signifies the end of how business strategies have developed, environmental and competencies anon The research conducted by Dr Bowen suggests that post-pandemic stakeholder engagement should be integral to creating an organisation's strategy. The "new normal" will bring about a host of difficulties, including unemployment, business failings, and government bailouts. To mitigate these problems, the development of new methods of strategic planning, incorporating CSR and

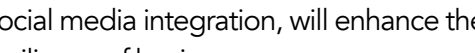

USE OF SOCIAL MEDIA IN STRATEGY

Social media is typically related to the marketing side of a company. However, though it is important as a marketing
tool, this undervalues the extent of
Responsibility

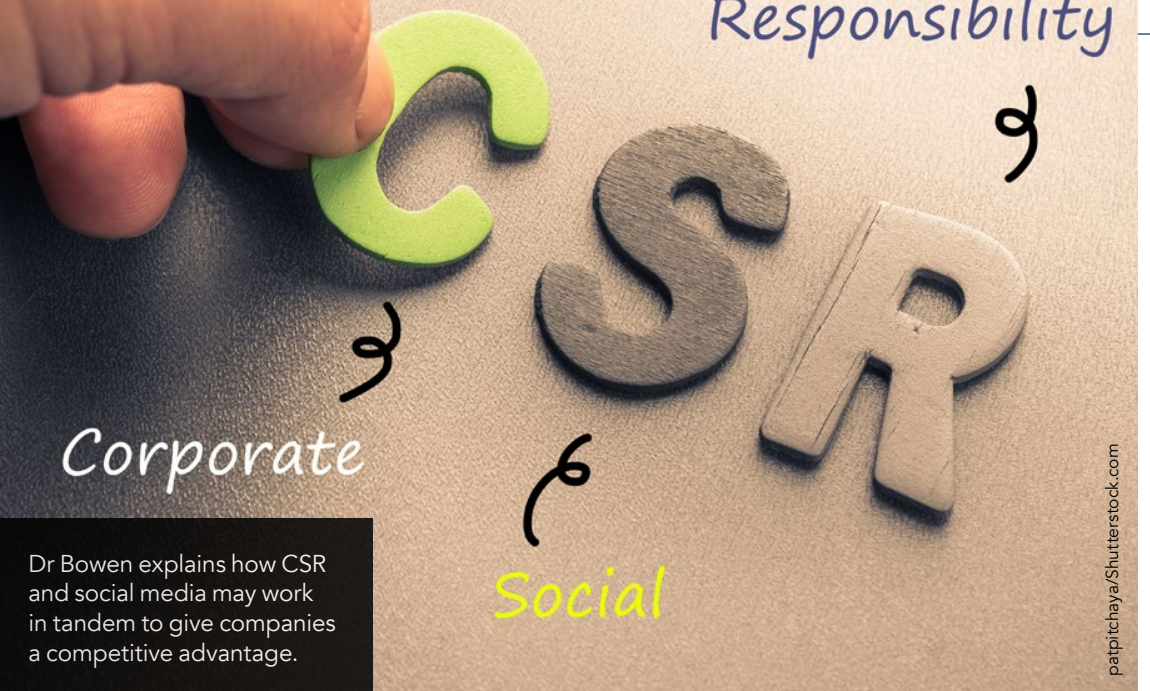

and how companies might improve the strategic methodologies. Governance is way companies are govern adsis. The to the decision-making process and should be central in building a suitable strategic plan

Big data analytics for businesses refers to collecting and interpreting data for better decision-making capabilities. When applied to strategic formulation, data analytics can give critical insights into the timing of decisions, market opportunities, and improving customer relationships.

INTEGRATING CSR AND SOCIAL MEDIA IN STRATEGIES Dr Bowen's research was based on a case study built on his participatory experience in a telecommunications company over two years. The study planning process through data analy povernance, CSR, and onlata analytics, communities (social media).

its applications. Through carefully customers on soctured interactions with can find common values with their client base and incorporate them into their strategy structure.

Social media as a mediator for cocreation between firms, managers, and customers has been a vital instrument companies. The more informationsharing and engagement there

Dr Bowen's research indicated that current strategic formulation systems are not fit for purpose.

is from stakeholders on a firm's social

media plattorms, the better the company

can shape their strategy and stakeholders

can help in the decision-making process.

This can make both customers and companies feel the they are building

\section{USE OF CSR IN STRATEGIES}

Corporate social responsibility is typically decide on their policies, planning and objectives to meet ethical, environmenta and social goals. CSR is not classically integrated into the strategy process. However, because of its importance in accounting for a company's broader effects on stakeholders - directly and indirectly - its integration could significantly improve strategy formulation.

Former CSR research indicates that combining CSR into strategy can improve society and improve economic performance. CSR can give and thus improve the fince advantage and thus improve their finances throug through better reputation, improved environmental and social performance, and employee retention.

GOVERNANCE AND

BUSINESS ANALYTICS Oovemance and business analytics are evaluating the curent strategy syst and

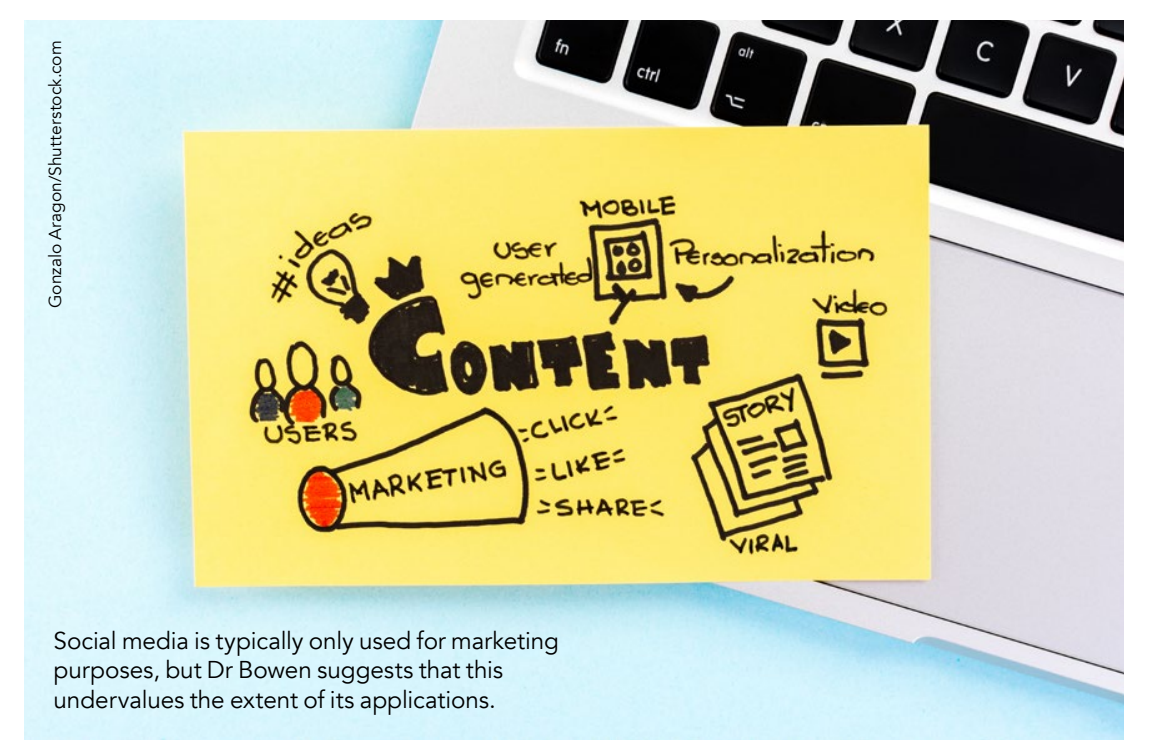

\section{ins}

\section{DEX}

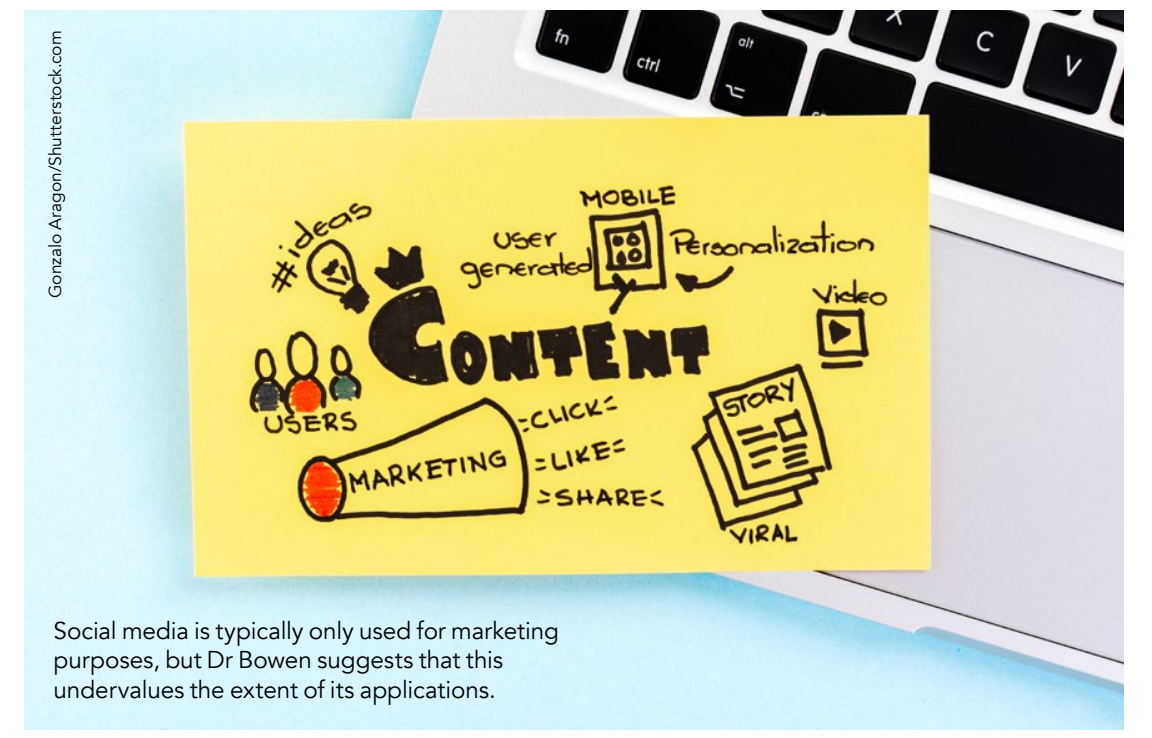

Social media is typically only used for marketing
purposes, but Dr Bowen suggests that this

company's strategic

作 each region's strategy.

The strengths of the company's strategy included that it utilised inform tion from 
